\title{
75. Compounds Containing Conjugated Triple Bond Linkage I. Synthesis of Phenyldiacetylene and Diphenyltetra-acetylene."
}

\author{
By Masazumi Nakagawa. \\ Department of Chemistry, Faculty of Science, Osaka University.
}

(Comm. by R. Majima, M.J.A., Dec. 12, 1950.)

As one of the polyacetylenic compounds, A. v. Baeyer ${ }^{11}$ has prepared earlier tetra-acetylene dicarboxylic acid, but its properties have not yet been thoroughly investigated, due to its instability. It is of much interest to find physical and chemical properties of such compounds whose molecule contain a long conjugated triple bonds in the straight bar of carbon atoms. The author has made a study of synthesis of polyacetylene compounds $(n=3,4,5 \cdots$ in I), taking in consideration of correlation of the structure of these to those of cumulene ${ }^{2)}$ and diphenylpolyene.") Tolan and diphenyldiacetylene, where $n$ is 1 and 2 respectively, have already been prepared in stable crystalline form.

Styryl methyl carbinol (II) was prepared from cinnamic aldehyde and methylmagnesium chloride by the Klages' method ${ }^{\text {t) }}$ with a slight modification, the carbinol then dehydrated

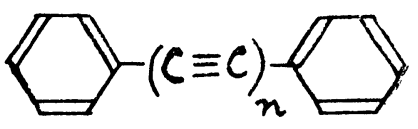

(I) to yield phenylbutadiene (III) and the latter treated with bromine to give tetrabromobutyl benzene (IV). The tetrabromide was dehydrobrominated by treating with sodamide in liquid ammonia and the reaction product distilled under the atomosphere of hydrogen. Phenyldiacetylene (V) thus obtained boiles at $37-40^{\circ} / 0.04 \mathrm{~mm} \mathrm{Hg}$., is a colorless oil with some odor, and polymerises readily at room temperature to give a brown tar. The oil becomes a white crystalline solid at $-70^{\circ}$ and can be kept as such for sometime without change. Its mercuric derivative, (VI), was prepared according to the method of J.R. Johnson ") and obtained in white silky needles, m. p. $188-189^{\circ}$ (decomp.). This was found to be very stable. Phenyldiacetylene gives off ethane when treated with ethylmagnesium bromide, giving the Grignard compound, and also forms the orange colored cuprous acetylide (VII) with cuprous ion. The cuprous derivative on oxidation with cupric chloride gave a yellow crystalline needles, m. p. 115-116 (colored brown), which was proved to be diphenyltetra-acetylene

* Presented before the meeting of the Kinki Chapter of the Chemical Society of Japan, Nov. 19, 1949. 


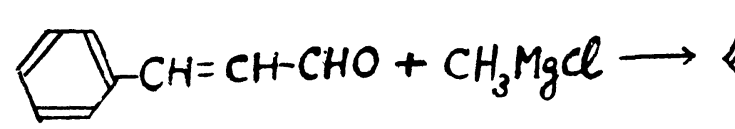

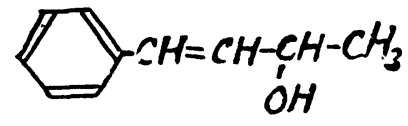

(II)

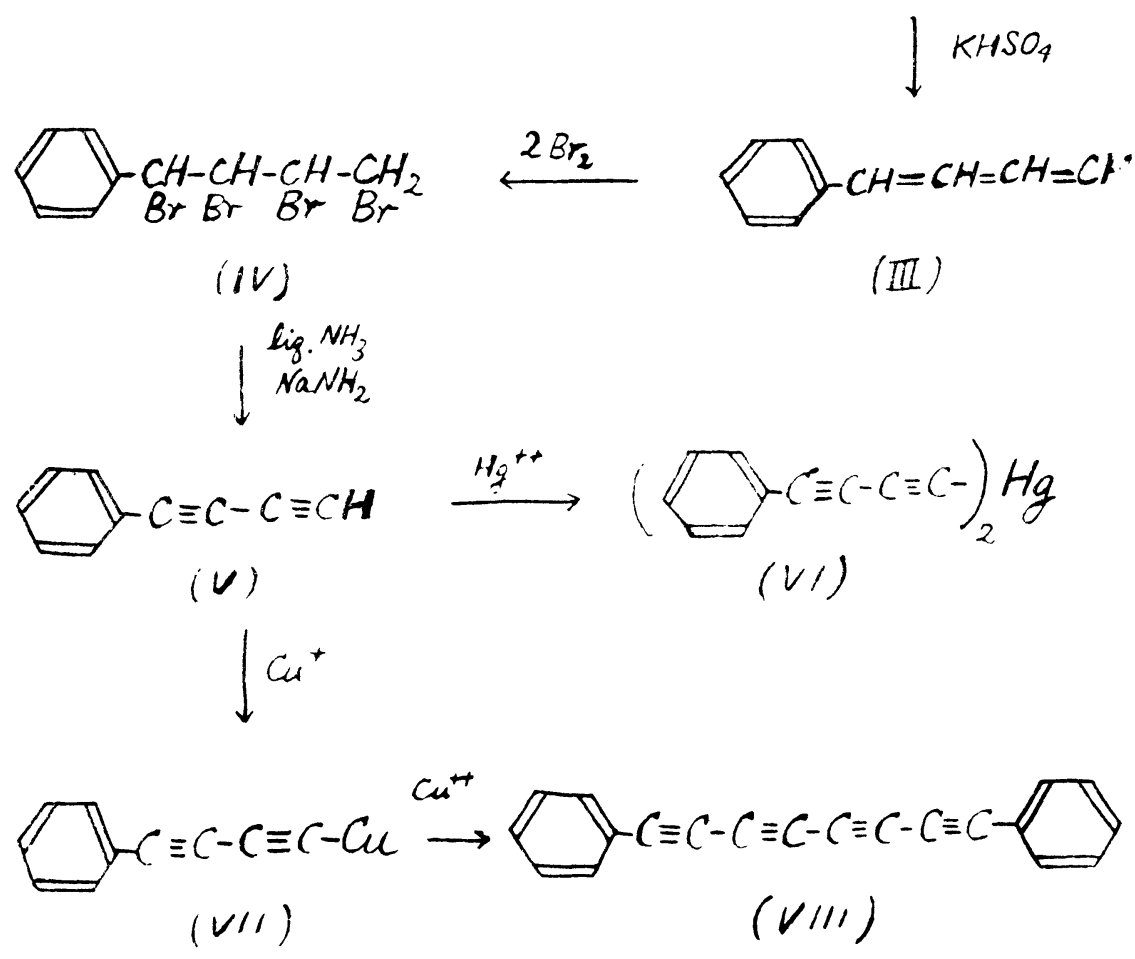

(VIII) from its elementary analysis, its molecular weight determination and the total amount of hydrogen absorbed on hydrogenation.

Ultraviolet absorption spectra of tolan, diphenyldiacetylene and diphenyl tetra-acetylene (in alcoholic solutions) move with a definite spacings toward longer wave length in the order mentioned, but their shapes are closely related (Fig. 1. Table I).

The crystals of diphenyltetra-acetylene are very stable, no change was observed when kept in a dark place for one year. It decomposes explosively when placed on a heated metallic plate, with emmission of light and a large amount of soot. It neither give a color reaction with concentrated solufuric acid nor molecular componnd with trinitrobenzene. It is interesting to find that this yellow crystalline hydrocarbon dissolves in polar solvents such as alcohol, acetone and methyl alcohol much more readily than do tolan and diphenyldiacetylene.

The synthesis of diphenyltriacetylene and diphenylpenta-acetylene are now being conducted by the author. 


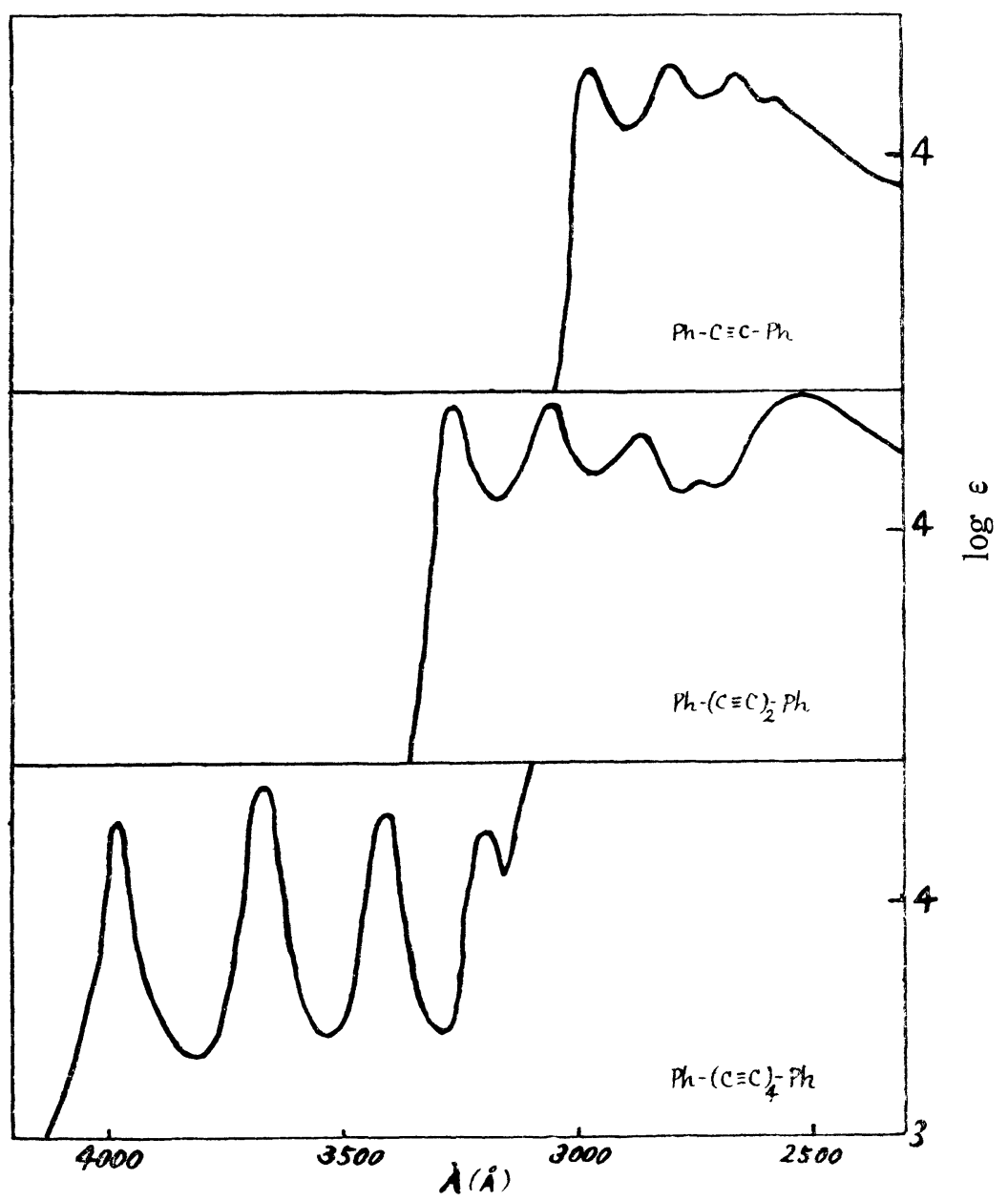

Fig. 1.

Table I

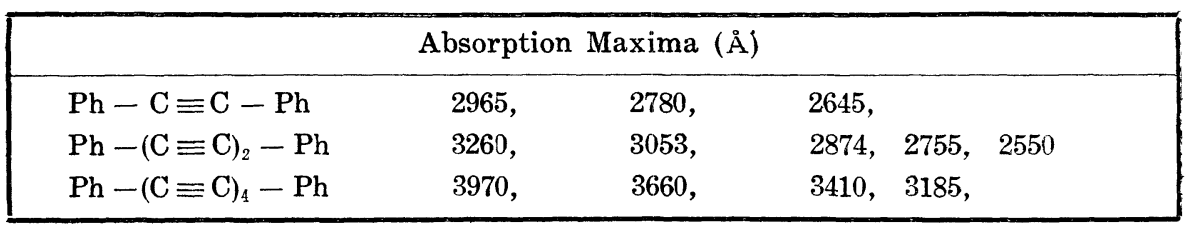

\section{Experimental.}

Styrylmethyl carbinol (II). - To the Grignard reagent prepared from $81 \mathrm{~g}$. of magnesium, $1700 \mathrm{cc}$. absolute ether and $150 \mathrm{cc}$. liquid methyl chloride was added, under cooling with ice, a solution of $270 \mathrm{~g}$. of cinnamic aldehyde in $300 \mathrm{cc}$. ether during a course of $2 \mathrm{hrs}$. 
After standing overnight, the Grignard reagent was decomposed by the addition of $130 \mathrm{~g}$. of ammonium chloride, and $350 \mathrm{cc}$. of water and the ether layer separated. The precipitate was washed three times wlth $400 \mathrm{cc}$. portion of ether and the ether washings added to the main ether solution. On removing the solvent, $270 \mathrm{~g}$. of crude styrylmethyl carbinol was obtained.

1-Phenylbutadiene (III).-To $270 \mathrm{~g}$. of the crude styrylmethyl carbinol were added $0.1 \mathrm{~g}$. of hydroquinone and $1.0 \mathrm{~g}$. of potassium bisulfate and the mixture distilled under reduced pressure. The distillate collected at $70^{\circ} / 9 \mathrm{~mm}$. (bath temp. $140^{\circ}$ ) was fractionated after drying; III was collected at $82.5^{\circ} / 9 \mathrm{~mm}$. The residue gave a further amount of III when distilled with the addition of $0.5 \mathrm{~g}$. of potassium bisulfate; total yield $160 \mathrm{~g}$. $(62 \%)$. Thirty grams of II boiling at $113^{\circ} / 7 \mathrm{~mm}$. was recovered.

Tetrabromobutylbenzene (IV).-A solution of $394 \mathrm{~g}$. of bromine in 400 cc. of chloroform was added dropwise to an ice-cold solution of III ( $160 \mathrm{~g}$.) in $1500 \mathrm{cc}$. of chloroform. After leaving overnight at room temperature, the reaction mixture was distilled to remove the solvent, a light yellow colored crystalline mass resulted. This was collected by filtration and recrystallized from petroleum ether; m. p. $60-120^{\circ}$, yield 450 g. $(81 \%)$. Repeated recrystallization from petroleum ether gave crystals melting at $142-7^{\circ}$, difficultly soluble, and crystals melting at $75-76^{\circ}$, readily soluble. This result is in close agreement with the observations made by A. Klagst) and C. N. Riiber. ${ }^{6)}$

Pnenyldiacetylene (V).-A suspension of $45 \mathrm{~g}$. of powdered III, m. p. $60-120^{\circ}$, in 300 ce. of absolute ether was added under stirring and cooling in the dry ice-alcohol bath to sodamide prepared from $18 \mathrm{~g}$. of sodium and $0.1 \mathrm{~g}$. of ferric nitrate in $450 \mathrm{cc}$. of liquid ammonia. The stirring was continued for $30 \mathrm{~min}$. after the addition was complete and then the cooling bath removed to allow ammonia to vaporize. Four hundred cubic milliliters of water was added with stirring to the residue, a brown ether insoluble material removed quickly by filtering through cotton, the ether layer washed with water and dried over potassium carbonate. The ether was removed under reduced pressure in the atmosphere of hydrogen and a brown oily residue remained was distilled in a current of hydrogen under high vacuum; b.p. $37-40^{\circ} / 0.04 \mathrm{~mm}$., $\mathrm{n}_{-i}^{\text {6.j }} 1.6232$, $\mathrm{d}_{1,5}$ 0.9778, $\mathrm{MR}_{D} 57.96$ (calc. 40.78), yield $8.5 \mathrm{~g}$. (67\%).

Phenyldiacetylene mercuric acetylide (VI).-A solution of $2.5 \mathrm{~g}$. of $\mathrm{V}$ in $50 \mathrm{cc}$. of alconol was added dropwise to a mixture of $3 \mathrm{~g}$. of mercuric cyanide, $3 \mathrm{~g}$. of potassium hydroxide and $200 \mathrm{cc}$. of water. The precipitate formed was collected by filtration and 
recrystallized from alcohol; white silky needles, m.p. $188-9^{\circ}$ (with decomposition), yield $4.5 \mathrm{~g}$.

Anal., according to the method of M.M. Otto.7) Sample, 0.3010 g., $\mathrm{HgS}, 0.1537 \mathrm{~g}$., Found : $\mathrm{Hg}, 44.05 \%$. Calculated for $\mathrm{C}_{20} \mathrm{H}_{10} \mathrm{Hg}: \mathrm{Hg}$, $44.47 \%$.

Phenyldiacetylene cuprous acetylide (VII). - To Ilsovay reagent, prepared from $8 \mathrm{~g}$. of cupric sulfate, $32 \mathrm{cc}$. of $28 \%$ ammonia, $24 \mathrm{~g}$. of hydroxylamine hydrochloride and $400 \mathrm{cc}$. of water was added a solution of $2 \mathrm{~g}$. of $\mathrm{V}$ in $150 \mathrm{cc}$. of alcohol. An orange colored precipitate formed was collected and washed with alcohol; yields were quantitative.

Diphenyltetra-acetylene (VIII). - Phenyldiacetylene cuprous acetylide prepared from $2 \mathrm{~g}$. of $\mathrm{V}$ was suspended in $125 \mathrm{cc}$. of water and to it was added $125 \mathrm{~g}$. of cupric chloride under mechanical stirring. After stirring for $5 \mathrm{hrs}$. and leaving it overnight, the precipitate formed was collected and extracted with ether and the ether removed by distillation. The crude yellow crystalline residue was treated with petroleum ether to separate an insoluble material from soluble. Repeated recrystallization of the soluble fraction from petroleum ether gave yellow needles; m. p. $115-116^{\circ}$, yield $1.1 \mathrm{~g}$.

Anal., Found:.C, 95.99\% 95.92\% H, 4.49\% 4.37\%. Calculated for $\mathrm{C}_{20} \mathrm{H}_{10}: \mathrm{C}, 96.0 \% \mathrm{H}, 4.0 \%$. Molecularweight. Sample 0.9626g., solvent, benzene $26.2 \mathrm{~g}$., $\Delta \mathrm{T}=0.761^{\circ}$. Found : 248. Calculated for $\mathrm{C}_{20} \mathrm{H}_{10}, 250$.

Catalytic reduction of diphenyltetra-acetylene. - VIII (0.3244 g.) dissolved in $30 \mathrm{cc}$. of alcohol was reduced in the presence of $0.1 \mathrm{~g}$. of palladium-charcoal (10\% palladium) at $26^{\circ}, 760 \mathrm{~mm}$. A total volume of hydrogen absorbed was $251 \mathrm{cc}$. $(7.9 \mathrm{~mol} ., 99 \%$ of the theory).

Acknowledgment. - The author is indebted to Prof. M. Kotake and Prof. T. Kaneko for their instructions given to the execution of this work. Thanks are also due to Mr. K. Nakamoto of the Tsuchida Laboratory of the Science Department for the determination of the absorption spectra.

\section{References.}

1) A. v. Baeyer: Ber., 18, 674, 2269 (1895).

2) R. Kuhn and K. Wallenfels: Ber., 71, 783 (1938).

3) R. Kuhn and A. Winterstein: Helv. Chim. Acta 11, 87 (1928).

4) A. Klages: Ber., 35, 2649 (1902).

5) J. R. Johnson and W. L. McEwer: J. Am. Chem. Soc., 48, 469 (1926).

6) C. N. Riiber: Ber., 36, 1404 (1903).

7) M. M. Otto : Ind. Eng. Chem., Anal. Ed., 4, 401 (1932). 